\title{
Pregnancy Outcomes in Vaharai, Batticaloa, Sri Lanka
}

\section{Thirukumar}

Obstetrics and Gynaecology, Department of Clinical Science, Faculty of Health Care Science, Eastern University, Sri Lanka, Vantharumoolai, Sri Lanka

Email:dr.thiru10@yahoo.com

How to cite this paper: Thirukumar, M. (2018) Pregnancy Outcomes in Vaharai, Batticaloa, Sri Lanka. Open Journal of Obstetrics and Gynecology, 8, 970-979. https://doi.org/10.4236/ojog.2018.811098

Received: July 25, 2018

Accepted: September 1, 2018

Published: September 4, 2018

Copyright ( 2018 by author and Scientific Research Publishing Inc. This work is licensed under the Creative Commons Attribution International License (CC BY 4.0).

http://creativecommons.org/licenses/by/4.0/

\begin{abstract}
The outcomes of pregnancy differ significantly between developing and developed countries. The poor use of prenatal and maternal health services can contribute to this difference. Materials and Methods: This descriptive cross-sectional study was conducted among all the pregnant mothers who attend to routine antenatal clinic for booking visit in medical officer health $(\mathrm{MOH})$ clinics at Vaharai $\mathrm{MOH}$ area for a period of one year. This study was aimed to identify the live birth rate and low birth weight incidence in the studied population and compare these figures with national figure. Results: This study included 695 pregnant mothers. $70.4 \%$ pregnant mothers attend their first antenatal booking visit before 8 weeks of gestational age. 611 pregnant mothers reached gestational age of more than 28 weeks. $13.7 \%$ pregnant mothers had 4 - 6 antenatal visits while $83.6 \%$ mothers had more than 7 visits. Among those who had body mass index (BMI) measurement, 39.6\% mothers had normal BMI and $43.6 \%$ pregnant mothers had low BMI, 16.8\% mothers had BMI above the normal range. Among those 611 mothers, 56.8\% had adequate weight gain $(>7.5 \mathrm{~kg})$ during their antenatal period, 3 of them had weight reduction and 11 mothers had not gain weight during their antenatal period. Majority $85.6 \%$ were not anaemic and $14.4 \%$ were anaemic. Regarding the current pregnancy outcome, $86.9 \%$ had live birth, $12.1 \%$ mothers had miscarriage, $0.9 \%$ (6) had intra uterine death (IUD) and $0.1 \%$ (1) had Hydatidiform mole. This study further showed that $22 \%$ of the pregnant mothers had their new-borns birth weight less than $2.5 \mathrm{~kg}$ at birth irrespective of their gestational age (low-birth weight babies). Conclusion: The lower live-birth rate, more incidence of low birth weight than the national figure of Sri Lanka is seen in the studied population of Vaharai. More incidence of anaemia, more teen-age pregnancies, failure to achieve recommended gestational weight gain during pregnancies despite frequent antenatal care, could be attributed to this adverse outcome.
\end{abstract}




\section{Keywords}

Pregnancy Outcomes, Batticaloa, Sri Lanka

\section{Introduction}

Good quality antenatal care improves outcomes for pregnant women and their babies [1]. The outcomes differ significantly between developing and developed countries [2]. It is believed that one of the major factors contributing to the high rate of adverse birth outcomes is the poor use of prenatal and maternal health services [3]. There are several factors determine the utilisation of antenatal care such as maternal education, employment, age, poverty, economic status of household, and access to the media [4] [5] [6] [7].

Antenatal care (ANC) remains one of the Safe Motherhood interventions that has the potential to significantly reduce maternal and perinatal mortalities [8]. Although Antenatal care (ANC) might not have the potential to predict and avert obstetric emergencies during pregnancy and childbirth, it exposes women to health education on risk factors and encourages them to be delivered by skilled health workers with health facilities. Therefore, antenatal period presents opportunities for reaching pregnant women with interventions to maximize maternal and neonatal health [9] [10].

Regular antenatal clinic visits provide health personnel with an opportunity to manage the pregnancy such as detection and treatment of pregnancy-induced hypertension, providing tetanus immunization [11] [12] [13], and micronutrient supplementation [14]. These steps are effective in improving pregnancy and neonatal outcomes [15]. Pregnant women in developing countries have an increased risk of maternal and perinatal mortality and morbidity [16] [17]. Low or middle-income countries bear $99 \%$ of all maternal and new-born deaths occurring in the world. The Poverty, lack of infrastructure and inadequate healthcare, are the main contributory factors for it [18] [19]. However, good quality antenatal care could prevent many of these complications.

The World Health Organization's (WHO) recommendation of at least fourantenatal clinic visits, spaced across regular intervals and with a skilled attendant has been shown to improve health outcomes for both expectant mothers and infants. To fully benefit from these interventions, it is important that women start ANC early on in their pregnancy. Several studies have shown that women who start to attend ANC early and continue regularly, are more likely to be assisted during delivery by skilled health workers compared to those who initiate ANC late and attend only few visits [20] [21].

Batticaloa district is in the Eastern province of Sri Lanka. This study was conducted in Vaharai area of Batticaloa. It has a population of 24,828 . This area was badly affected during 30 years of civil war. Most of the people from this area are poor. The author conducts outreached antenatal clinic in the area and noted 
poor pregnancy parameters, therefore this study was planned to study the pregnancy outcome and compare with the national figures.

\section{Materials and Methods}

This descriptive cross-sectional study was conducted among all the pregnant mothers who attended to routine antenatal clinic for booking visit in Medical Officer Health $(\mathrm{MOH})$ clinics at Vaharai $\mathrm{MOH}$ area and comprises of 10 Public Health Midwife (PHM) areas. This study was aimed to identify the live birth rate and low birth weight incidence in the studied population and compare these figures with national figure.

In Sri Lanka antenatal care package system, when a woman embarks on pregnancy she is registered for antenatal care and two sets of records are maintained; " $\mathrm{A}$ " card and " $\mathrm{B}$ " card. The " $\mathrm{A}$ " card is hand held by pregnant mothers and shown to health care workers during antenatal clinic visit. The "B" is maintained by midwives for record keeping. The entire $\mathrm{B}$ cards during this study period of one year from April 2015 to April 2016 were collected for this study. The gestational age of booking visit, total number of antenatal visits, their booking visit BMI, total weight gaining, Haemoglobin level and outcome of the index pregnancy such as birthweight, live birth rate were assessed along with basic demographic details. Data was extracted from the records available. Data extraction sheets were used to obtain data. All data were coded and entered in to SPSS 21 package and analysed.

\section{Results}

This study included 695 pregnant mothers. Among them majority were Tamil $(\mathrm{n}=661 ; 95.1 \%)$ and belong to $19-35$-year (average) age group $(\mathrm{n}=587$; $84.5 \%)$. Majority of pregnant mothers studied up to ordinary level. $(\mathrm{n}=484$; 69.6\%) (Table 1).

In this study, majority of pregnant mothers $(70.4 \%)$ attended their first antenatal booking visit before 8 weeks of gestation (Table 2).

Out of 695 pregnant mothers, 611 pregnant mothers reached gestational age of more than 28 weeks (Table 3). They were analysed for adequate number of ANC visits. 13.7\% (84) pregnant mothers had 4 - 6 antenatal visits while 83.6\% (511) mothers had more than 7 visits. During their booking visit $85.76 \%$ of the mothers had their BMI checked and $14.24 \%$ (99) pregnant mothers had not have BMI measurement. Among those who had BMI measurement, 39.6\% mothers (260) had normal BMI and 43.6\% (236) pregnant mothers had low BMI. On the other hand, $16.8 \%$ (100) mothers had BMI above the normal range (Table 4).

Among those 611 mothers, 347 (56.8\%) had adequate weight gain $(>7.5 \mathrm{~kg})$ during their antenatal period, 3 of them had weight reduction and 11 mothers had not gain weight during their antenatal period (Table 5). When haemoglobin level at booking visit is considered, 7\% pregnant mother's haemoglobin level measurement report is not recorded in the available B Card. Other mothers $\mathrm{Hb}$ 
Table 1. Characteristics of studied pregnant population.

\begin{tabular}{|c|c|c|}
\hline & Frequency & Percentage (\%) \\
\hline \multicolumn{3}{|l|}{ Ethnicity } \\
\hline Tamil & 661 & 95.1 \\
\hline Muslim & 29 & 4.2 \\
\hline Sinahala & 05 & 0.7 \\
\hline \multicolumn{3}{|l|}{ Age category } \\
\hline Teenage ( $<19$ years) & 75 & 10.8 \\
\hline Average (19 - 35 years) & 587 & 84.5 \\
\hline Elderly (>35 years) & 33 & 4.7 \\
\hline \multicolumn{3}{|l|}{ Parity } \\
\hline P1 & 271 & 39.0 \\
\hline $\mathrm{P} 2$ & 227 & 32.7 \\
\hline $\mathrm{P} 3$ & 112 & 16.1 \\
\hline $\mathrm{P} 4$ & 57 & 8.2 \\
\hline P5 and above & 28 & 4.0 \\
\hline \multicolumn{3}{|l|}{ Educational level } \\
\hline No schooling & 15 & 2.2 \\
\hline Upto grade 5 & 154 & 22.2 \\
\hline Upto GCE O/L & 484 & 69.6 \\
\hline Upto GCE A/L & 42 & 6.0 \\
\hline
\end{tabular}

Table 2. Timing of booking visit.

\begin{tabular}{ccc}
\hline Booking POA & Frequency & $\%$ \\
\hline$<8$ weeks & 489 & 70.4 \\
$8-12$ weeks & 135 & 19.4 \\
$>12$ weeks & 71 & 10.2 \\
\hline
\end{tabular}

Table 3. Total number of ANC visits of pregnant mothers reached POA $>28$ weeks.

\begin{tabular}{ccc}
\hline Total number of ANC visits & Frequency & $\%$ \\
\hline$<4$ & 16 & 2.6 \\
$4-6$ & 84 & 13.7 \\
$>7$ & 511 & 83.6 \\
Total & 611 & 100.0 \\
\hline
\end{tabular}

Table 4. Distribution of BMI at booking visit.

\begin{tabular}{ccc}
\hline Booking BMI & Frequency & $\%$ \\
\hline$<18.5 \mathrm{~kg} / \mathrm{m}^{2}$ & 236 & 39.6 \\
$18.5-23.5 \mathrm{~kg} / \mathrm{m}^{2}$ & 260 & 43.6 \\
$>23.5 \mathrm{~kg} / \mathrm{m}^{2}$ & 100 & 16.8 \\
\hline
\end{tabular}

$\mathrm{N}=99$ of pregnant mothers did not have BMI value in their records. 
Table 5. Total weight gain of pregnant mothers reached POA $>28$ weeks.

\begin{tabular}{ccc}
\hline Total weight gain & Frequency & $\%$ \\
\hline$<5$ & 83 & 13.6 \\
$5-7.5$ & 167 & 27.3 \\
$7.5-10$ & 190 & 31.1 \\
$>10$ & 157 & 25.7 \\
Weight reduction & 03 & 0.5 \\
No weight gain & 11 & 1.8 \\
Total & 611 & 100.0 \\
\hline
\end{tabular}

$\mathrm{N}=84$ of them had miscarriage ( $<28$ weeks).

reports showed that majority $(85.6 \%)$ were not anaemic and $14.4 \%(\mathrm{~N}=92)$ were anaemic. Among the anaemic mothers $8.4 \%$ were mild, $5.2 \%$ were moderate $\& 0.8 \%$ severe anaemic (Table 6 ).

This study also shows that out of 695 pregnant mothers, $18.4 \%$ (128) mothers had miscarriage or stillbirth or neonatal death or IUD in their previous pregnancy (Table 7). Regarding the current pregnancy outcome, $86.9 \%$ (604) had live birth, $12.1 \%$ (84) mothers had miscarriage, $0.9 \%$ (6) had IUD and $0.1 \%$ (1) had Hydatitiformmole. This study further showed that $22 \%$ of the pregnant mothers had their new-borns birth weight less than $2.5 \mathrm{~kg}$ at birth irrespective of their gestational age (low-birth weight) babies (Table 8).

\section{Discussion}

In Sri Lanka, total live birth rate was $93.7 \%$ in 2015 while this studied population showed live birth rate was $86.9 \%$ during the same period. The low birth weight percentages among new born was $11.4-16.0$ in 2015 in Sri Lanka but this study showed that $22 \%$ of the new born were low birth weight in Vaharai area [22]. Thus, this studied population of Vaharai had lower live birth rate and more low birth rate than the national figure.

In Sri Lanka $77.1 \%$ of pregnancies had their registration before 8 weeks of pregnancy in 2015. But in this studied pregnant mother, 70.4\% attended their first antenatal booking visit before POA of 8 weeks.

The "booking appointment" involves a health and social care assessment of needs and risks to identify pregnant mothers who needs additional care and support during her pregnancy and the provision of information regarding pregnancy and the pregnancy care pathway, including information on screening tests. The pregnant mothers are advised to attend their first appointment before the end of their first trimester, preferably by 10 weeks of pregnancy [23]. The percentage of pregnant women attending the booking appointment by completed 12 weeks of pregnancy has been set as an indicator of access for benchmarking and improving local services [24]. Several studies have identified socio-demographic predictors of late initiation of antenatal care for pregnant women such as young age, high parity, lower socio-economic status indicating 
Table 6. Prevalence of anaemia among age categories and Parities.

\begin{tabular}{ccccc}
\hline & \multicolumn{2}{c}{ Anaemic mothers } & \multicolumn{2}{c}{ Non-Anaemic mothers } \\
\cline { 2 - 5 } & Frequency & Percentage (\%) & Frequency & Percentage (\%) \\
\hline Age category & 10 & 13.7 & 63 & 86.3 \\
\hline Teenage (<19 years) & 80 & 14.9 & 458 & 85.1 \\
Average (19 - 35 years) & 02 & 6.7 & 28 & 93.3 \\
Elderly (>35 years) & & & & \\
\hline Parity & 46 & 18.0 & 210 & 82.0 \\
\hline P1 & 27 & 13.2 & 178 & 86.8 \\
P2 & 09 & 8.7 & 95 & 91.3 \\
P3 & 07 & 13.5 & 45 & 86.5 \\
P4 & 03 & 12.5 & 21 & 87.5 \\
\hline P5 and above & & & & \\
\hline
\end{tabular}

$\mathrm{N}=54$ of pregnant mothers did not undergone measurement of haemoglobin level at booking visit.

Table 7. Miscarriage or still birth or Neonatal death or IUD in previous pregnancy.

\begin{tabular}{ccc}
\hline & Frequency & $\%$ \\
\hline Yes & 128 & 18.4 \\
No & 567 & 81.6 \\
\hline
\end{tabular}

Table 8. Distribution of current pregnancy outcome and birth weight.

\begin{tabular}{ccc}
\hline Current pregnancy outcome & Frequency & $\%$ \\
\hline Miscarriage & 84 & 12.1 \\
Live birth & 604 & 86.9 \\
IUD & 06 & 0.9 \\
Hydatitiform mole & 01 & 0.1 \\
Total & 695 & 100.0 \\
\hline Birth weight of baby-Current pregnancy & & 0.7 \\
\hline $1000-1499$ & 04 & 21.3 \\
$1500-2499$ & 129 & 78.0 \\
$>2500$ & 471 & 100.0 \\
\hline Available samples other than miscarriage, & 604 & \\
IUD and Hydatitiform mole & & \\
\hline
\end{tabular}

that late initiation of antenatal care is more likely amongst groups of women already known to be at higher risk of adverse pregnancy out comes [25] [26] [27]. There are several personal, structural and service-related factors that delay or prevent access to antenatal care [28]. To identify how such factors can be effectively addressed, an understanding of local contexts and of both factors that promote and delay the early initiation of antenatal care is needed.

In 2015, about $79.9 \%$ of pregnant mothers in Sri Lanka had their BMI as- 
sessed. This study showed that $85.76 \%$ of the mothers had their BMI checked during their booking visit. So, data truly reflect distribution of BMI among the studied population. This study shows that $43.6 \%$ of the studied population had low BMI (less than 18.5) at booking visit while in the country figure was $20.2 \%$ during the same study period.

While the $55.7 \%$ of pregnant population of Srilanka in their booking visiting had normal BMI, in the study area of Vaharai only $39.6 \%$ pregnant mothers had normal BMI. In addition, percentage of overweight (BMI more than 25) women also less in the study area than that of in the country $16.8 \%$ and $21.3 \%$ respectively. So, this study shows that many women embarked pregnancy with suboptimal pre-pregnancy weight. Pre-pregnancy body mass index is an important predictor of birth weight. American Institute of Medicine introduced weight gain recommendations for pregnant women with different recommendations for underweight, normal weight, overweight and obese women [29].

This study shows that among those 611 mothers, 56.8\% (347) had adequate weight gain (equal or more than $7.5 \mathrm{~kg}$ ) during their antenatal period. One study in Kegalle District of Sri Lanka shows that despite frequent antenatal care, majority of mothers did not achieve recommended gestational weight gain [30]. As per 2012 Population Census in Sri Lanka, the mean age at marriage of females is 23.4 years. As teen marriage causes several medical, social and obstetric problems, early marriage during teen age is highly discouraged. In Sri Lanka, the teenage pregnant mothers (less than 20 years) out of all registered pregnancies were $5.3 \%$ in 2015 [22]. This study shows $10.8 \%$ of the pregnancies were teen age group.

The level of education of women influences the ANC coverage in low income countries. A study in Ethiopia shows that ANC utilization by skilled care providers increases as the level of education of woman increases; only $25 \%$ by women who had no education, compared with $90 \%$ of those who had higher than secondary level education [31]. In Sri Lanka a pregnant mother had an average 6.3 visits during her pregnancy in 2014. In this study $13.7 \%$ (84) pregnant mothers had 4 - 6 antenatal visits and 83.6\% (511) mothers had more than 7 visits. So, most of pregnant women received adequate antenatal clinic visits and comparable to rest of the country pregnant population. This study shows that even though majority of pregnant mothers studied up to GCE O/L ( $n=484$; $69.6 \%)$ they used the existing services very well. It shows good strength of the antenatal care services in Sri Lanka.

\section{Conclusions}

The lower live-birth rate, the more incidence of low birth weight than the national figure of Sri Lanka was seen in the studied population of Vaharai. More incidence of anaemia, more teen-age pregnancies, failure to achieve recommended gestational weight gain during pregnancies despite frequent antenatal care, could be attributed to this adverse outcome. Although this study shows 
women who begin their antenatal care late in pregnancy future qualitative studies can provide insights into women's views and experiences of seeking care and of accessing and engaging with antenatal care services.

Intervention is required to optimize pre-pregnancy weight and correction of anaemia through proper nutritional care and it should be continued throughout during pregnancy.

Personal resources in terms of time, money and social support are considered alongside service provision issues including the perceived quality of care, the trustworthiness and cultural sensitivity of staff and feelings of mutual respect. The respectful care in a friendly environment would establish good rapport between care providers and pregnant mothers. This is an important factor to encourage pregnant mother to initiate care early, especially if the pregnant mothers are from underprivilege or marginalized society.

\section{Conflicts of Interest}

The authors declare no conflicts of interest regarding the publication of this paper.

\section{References}

[1] Hollowell, J., Oakley, L., Vigurs, C., Barnett-Page, E., Kavanagh, J. and Oliver, S. (2012) Increasing the Early Initiation of Antenatal Care by Black and Minority Ethnic Women in the United Kingdom: A Systematic Review and Mixed Methods Synthesis of Women's Views and the Literature on Intervention Effectiveness. National Perinatal Epidemiology Unit, University of Oxford.

[2] Amouzou, A., Kozuki, N. and Gwatkin, D.R. (2014) Where Is the Gap? The Contribution of Disparities within Developing Countries to Global Inequalities in Under-Five Mortality. BMC Public Health, 14, 216.

https://doi.org/10.1186/1471-2458-14-216

[3] Bilenko, N., Hammel, R. and Belmaker, I. (2007) Utilization of Antenatal Care Services by a Semi-Nomadic Bedouin Arab Population: Evaluation of the Impact of a Local Maternal and Child Health Clinic. Maternal and Child Health Journal, 11, 425-430. https://doi.org/10.1007/s10995-007-0193-4

[4] Adekanle, D.A. and Isawumi, A.I. (2008) Late Antenatal Care Booking and Its Predictors among Pregnant Women in South Western Nigeria. Online Journal of Health and Allied Sciences, 7, 1-6.

[5] Awusi, V.O., Anyanwu, E.B. and Okeleke, V. (2009) Determinants of Antenatal Care Services Utilization in Emevor Village, Nigeria. Benin Journal of Postgraduate Medicine, 1, 21-26.

[6] Saxena, N.C., Chandhiok, N., Dhillon, B.S. and Kambo, I. (2006) Determinants of Antenatal Care Utilization in Rural Areas of India: A Cross-Sectional Study of 28 Districts (An ICMR Task Force Study). Journal of Obstetrics and Gynaecology of India, 56, 47-52.

[7] Tann, C.J., Kizza, M., Morison, L., Mabey, D., Muwanga, M., Grosskurth, H. and Elliott, A.M. (2007) Use of Services and Delivery Care in Entebbe, Uganda: A Community Survey. BMC Pregnancy and Childbirth, 7, 23.

[8] Oladapo, O. and Osiberu, M. (2009) Do Sociodemographic Characteristics of Preg- 
nant Women Determine Their Perception of Antenatal Care Quality? Maternal and Child Health Journal, 13, 505-511. https://doi.org/10.1007/s10995-008-0389-2

[9] Ekele, B.A. and Tunau, K.A. (2007) Place of Delivery among Women Who Had Antenatal Care in a Teaching Hospital. Acta Obstetricia et Gynecologica Scandinavica, 86, 627-630. https://doi.org/10.1080/00016340601134622

[10] Simkhada, B., van Teijlingen, E.R., Porter, M. and Simkhada, P. (2008) Factors Affecting the Utilization of Antenatal Care in Developing Countries: Systematic Review of the Literature. Journal of Advanced Nursing, 61, 244-260. https://doi.org/10.1111/j.1365-2648.2007.04532.x

[11] Overbosch, G.B., Nsowah-Nuamah, N.N.N., van den Boom, G.J.M. and Damnyag, L. (2004) Determinants of Antenatal Care Use in Ghana. Journal of African Economies, 13, 277-301. https://doi.org/10.1093/jae/ejh008

[12] Raatikainen, K., Heiskanen, N. and Heinonen, S. (2007) Under-Attending Free Antenatal Care Is Associated with Adverse Pregnancy Outcomes. BMC Public Health, 7, 268. https://doi.org/10.1186/1471-2458-7-268

[13] Titaley, C.R., Dibley, M.J. and Roberts, C.L. (2010) Factors Associated with Underutilization of Antenatal Care Services in Indonesia: Results of Indonesia Demographic and Health Survey 2002/2003 and 2007. BMC Public Health, 10, 485-494. https://doi.org/10.1186/1471-2458-10-485

[14] Magadi, M.A. and Madise, N.J. (2000) Frequency and Timing of Antenatal Care in Kenya: Explaining the Variations between Women of Different Communities. Social Science \& Medicine, 51, 551-561. https://doi.org/10.1016/S0277-9536(99)00495-5

[15] Carroli, G., Rooney, C. and Villar, J. (2001) How Effective Is Antenatal Care in Preventing Maternal Mortality and Serious Morbidity? An Overview of the Evidence. Paediatric and Perinatal Epidemiology, 15, 1-42. https://doi.org/10.1046/j.1365-3016.2001.0150s1001.x

[16] International Federation of Red Cross and Red Crescent Societies (2013) Maternal, Newborn and Child Health Framework. Geneva. http://www.ifrc.org/PageFiles/93927/1232600-MNCH\%20Framework\%20report_L R\%20(2).pdf

[17] Tuncalp, O., Souza, J.P., Hindin, M.J., Santos, C.A., Oliveria, T.H., et al. (2014) Education and Severe Maternal Outcomes in Developing Countries: A Multi Country Cross Sectional Survey. BJOG: An International Journal of Obstetrics \& Gynaecology, 121, 57-65. https://doi.org/10.1111/1471-0528.12634

[18] Wang, H., Liddell, C.A., Coates, M.M., Mooney, M.D., Levitz, E.C., et al. (2014) Global, Regional and National Levels of Neonatal, Infant and under-5 Mortality during 1990-2013: A Systematic Analysis for the Global Burden of Disease Study 2013. The Lancet, 384, 957-979. https://doi.org/10.1016/S0140-6736(14)60497-9

[19] Peterson, H.B., Haidar, J., Merialdi, M., Say, L., Gülmezoglu, A.M., et al. (2012) Preventing Maternal and Newborn Deaths Globally: Using Innovation and Science to Address Challenges in Implementing Life-Saving Interventions. Obstetrics \& Gynecology, 120, 636-642. https://doi.org/10.1097/AOG.0b013e3182632cc1

[20] Mpembeni, R.N., Killewo, J.Z., Leshabari, M.T., Massawe, S.N., Jahn, A., Mushi, D. and Mwakipa, H. (2007) Use Pattern of Maternal Health Services and Determinants of Skilled Care during Delivery in Southern Tanzania: Implications for Achievement of MDG-5 Targets. BMC Pregnancy Childbirth, 7, 29. https://doi.org/10.1186/1471-2393-7-29

[21] Rockers, P.C., Wilson, M.L., Mbaruku, G. and Kruk, M.E. (2009) Source of Ante- 
natal Care Influences Facility Delivery in Rural Tanzania: A Population-Based Study. Maternal and Child Health Journal, 13, 879-885.

https://doi.org/10.1007/s10995-008-0412-7

[22] Annual Health Bulletin 2015.

[23] Antenatal Care for Uncomplicated Pregnancies. Clinical Guideline. https://www.nice.org.uk/guidance/cg62?UNLID=91207100120183120111

[24] NHS Digital (Health and Social Care Information Centre).

[25] Corbett, S., et al. (2014) Barriers to Early Initiation of Antenatal Care in a Multi-Ethnic Sample in South Auckland, New Zealand. New Zealand Medical Journal, 127, 53-61.

[26] Baker, E.C. and Rajasingam, D. (2012) Using Trust Databases to Identify Predictors of Late Booking for Antenatal Care within the UK. Public Health, 126, 112-116. https://doi.org/10.1016/j.puhe.2011.10.007

[27] Cresswell, et al. (2013) Predictors of the Timing of Initiation. Pregnancy and Childbirth, 13, 103 .

[28] Downe, S., Finlayson, K., Walsh, D. and Lavender, T. (2009) Weighing up and Balancing out: A Meta-Synthesis of Barriers to Antenatal Care for Marginalised Women in High-Income Countries. BJOG, 116, 518-529.

[29] Institute of Medicine NAoS (1990) Nutrition during Pregnancy. National Academy Press, Washington DC.

[30] Gunawardane, D.A. and Dharmaratne, S.D. (2014) Weight Gain during Pregnancy; How Much Is Enough? Peradeniya University International Research Sessions, Peradeniya, 4-5 July 2014, Vol. 18.

https://www.researchgate.net/publication/263698363_weight_gain_during_pregnan cy_how_much_is_enough

[31] Tarekegn, S.M., Lieberman, L.S. and Giedraitis, V. (2014) Determinants of Maternal Health Service Utilization in Ethiopia: Analysis of the 2011 Ethiopian Demographic and Health Survey. BMC Pregnancy and Childbirth, 14, 161.

https://doi.org/10.1186/1471-2393-14-161 